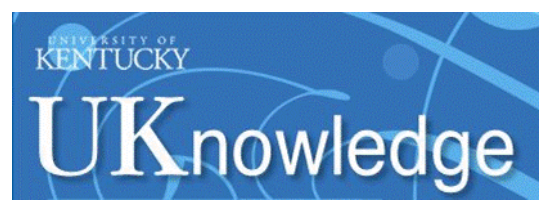

University of Kentucky

UKnowledge

Mechanical Engineering Faculty Publications

Mechanical Engineering

3-22-2018

\title{
Influence of SLM on Compressive Response of NiTi Scaffolds
}

Narges Shayesteh Moghaddam

The University of Toledo

Soheil Saedi

University of Kentucky, soheil.saedi@uky.edu

Amirhesam Amerinatanzi

The University of Toledo

Ahmadreza Jahadakbar

The University of Toledo

Sayed Ehsan Saghaian

University of Kentucky

See next page for additional authors

Follow this and additional works at: https://uknowledge.uky.edu/me_facpub

Part of the Materials Science and Engineering Commons, and the Mechanical Engineering Commons Right click to open a feedback form in a new tab to let us know how this document benefits you.

\section{Repository Citation}

Moghaddam, Narges Shayesteh; Saedi, Soheil; Amerinatanzi, Amirhesam; Jahadakbar, Ahmadreza;

Saghaian, Sayed Ehsan; Karaca, Haluk E.; and Elahinia, Mohammad, "Influence of SLM on Compressive Response of NiTi Scaffolds" (2018). Mechanical Engineering Faculty Publications. 50.

https://uknowledge.uky.edu/me_facpub/50

This Conference Proceeding is brought to you for free and open access by the Mechanical Engineering at UKnowledge. It has been accepted for inclusion in Mechanical Engineering Faculty Publications by an authorized administrator of UKnowledge. For more information, please contact UKnowledge@lsv.uky.edu. 


\title{
Influence of SLM on Compressive Response of NiTi Scaffolds
}

\author{
Digital Object Identifier (DOI) \\ https://doi.org/10.1117/12.2305251
}

\section{Notes/Citation Information}

Published in Proceedings of SPIE, v. 10596, Behavior and Mechanics of Multifunctional Materials and Composites XII, article $105960 \mathrm{H}$, p. 1-7.

(C) 2018 SPIE. One print or electronic copy may be made for personal use only. Systematic reproduction and distribution, duplication of any material in this paper for a fee or for commercial purposes, or modification of the content of the paper are prohibited.

Narges Shayesteh Moghaddam, Soheil Saedi, Amirhesam Amerinatanzi, Ahmadreza Jahadakbar, Ehsan Saghaian, Haluk Karaca, and Mohammad Elahinia, "Influence of SLM on compressive response of NiTi scaffolds," Proc. SPIE 10596, Behavior and Mechanics of Multifunctional Materials and Composites XII, 105960H (March 22, 2018). DOI: https://doi.org/10.1117/12.2305251

The copyright holder has granted the permission for posting the article here.

\section{Authors}

Narges Shayesteh Moghaddam, Soheil Saedi, Amirhesam Amerinatanzi, Ahmadreza Jahadakbar, Sayed Ehsan Saghaian, Haluk E. Karaca, and Mohammad Elahinia 


\section{Influence of SLM on compressive response of NiTi scaffolds}

\section{Narges Shayesteh Moghaddam, Soheil Saedi, Amirhesam Amerinatanzi, Ahmadreza Jahadakbar, Ehsan Saghaian, et al.}

Narges Shayesteh Moghaddam, Soheil Saedi, Amirhesam Amerinatanzi, Ahmadreza Jahadakbar, Ehsan Saghaian, Haluk Karaca, Mohammad Elahinia, "Influence of SLM on compressive response of NiTi scaffolds," Proc. SPIE 10596, Behavior and Mechanics of Multifunctional Materials and Composites XII, 105960H (22 March 2018); doi: 10.1117/12.2305251 Health Monitoring, 2018, Denver, Colorado, United States 


\title{
Influence of SLM on Compressive Response of NiTi Scaffolds
}

\author{
Narges Shayesteh Moghaddam ${ }^{\mathrm{a}}$, Soheil Saedi ${ }^{\mathrm{b}}$, Amirhesam Amerinatanzi ${ }^{\mathrm{a}}$, Ahmadreza Jahadakbar ${ }^{\mathrm{a}}$, \\ Ehsan Saghaian ${ }^{\mathrm{b}}$, Haluk Karacab, Mohammad Elahinia ${ }^{* a}$ \\ ${ }^{a}$ Dynamic and Smart Systems Laboratory, Mechanical Industrial and Manufacturing Engineering \\ Department, The University of Toledo, OH, 43606 \\ ${ }^{\mathrm{b}}$ Department of Mechanical Engineering, University of Kentucky, Lexington, KY 40506-0503
}

\begin{abstract}
Porous Nickel-Titanium shape memory alloys (NiTi-SMAs) have attracted much attention in biomedical applications due to their high range of pure elastic deformability (i.e., superelasticity) as well as their bone-level modulus of elasticity ( $E \approx 12-20 \mathrm{GPa}$ ). In recent years, Selective Laser Melting (SLM) has been used to produce complex NiTi components. The focus of this study is to investigate the superelasticity and compressive properties of SLM NiTi-SMAs. To this aim, several NiTi components with different level of porosities (32- 58\%) were fabricated from $\mathrm{Ni}_{50.8} \mathrm{Ti}$ (at. \%) powder via SLM PXM by Phenix/3D Systems, using optimum processing parameter (Laser power- $\mathrm{P}=250 \mathrm{~W}$, scanning speed-v=1250 $\mathrm{mm} / \mathrm{s}$, hatch spacing-h $=120 \mu \mathrm{m}$, layer thickness- $\mathrm{t}=30 \mu \mathrm{m}$ ). To tailor the superelasticity behavior at body temperature, the samples were solution annealed and aged for $15 \mathrm{~min}$ at $350^{\circ} \mathrm{C}$. Then, transformation temperatures (TTs), superelastic response, and cyclic behavior of NiTi samples were studied. As the porosity was increased, the irrecoverable strain was observed to be higher in the samples. At the first superelastic cycle, 3.5\%, 3.5\%, and $2.7 \%$ strain recovery were observed for the porosity levels of $32 \%, 45 \%$, and $58 \%$, respectively. However, after 10 cycles, the superelastic response of the samples was stabilized and full strain recovery was observed. Finally, the modulus of elasticity of dense SLM NiTi was decreased from $47 \mathrm{GPa}$ to $9 \mathrm{GPa}$ in the first cycle by adding $58 \%$ porosity.
\end{abstract}

Keywords: Porous NiTi, Selective Laser Melting, Superelasticity, Compressive Response.

\section{INTRODUCTION}

NiTi alloys are great candidates for orthopedic implants as they demonstrate unique shape memory effect and superelasticity, low modulus of elasticity (i.e., moduli, stiffness) (40-60 GPa), and biocompatibility [1, 2]. Low modulus of elasticity at the level of bone is particularly desirable as it decreases the rate of implant failure resulting from stress shielding effect [3]. Stress shielding effect is defined as the abnormal stress distribution between the high stiff implant and the surrounding bone. For example, Ti-6Al-4V implants demonstrate high modulus of elasticity of $112 \mathrm{GPa}$, much higher than that of the human cortical (12-20 GPa) or cancellous ( $<3 \mathrm{GPa}$ ) bone. This high modulus of elasticity causes the implant to carry the major portion of the loading while shielding the surrounding bone from carrying the load, which, in turn, result in bone resorption around the implant according to Wolf's low $[4,5]$. The common practice to decrease the modulus of elasticity of the implants to the level of bone is to introduce porosity into the metallic implants [6-8]. Porosity level, pore shape, pore size, and pore distribution are among the influencing factors on the modulus of elasticity of implants $[9,10]$. In addition to modulus of elasticity tuning, porosity can enhance the bone ingrowth and improve bone/implant interconnections [4, 11].

In recent years, additive manufacturing (AM) techniques have attracted much attention since they enable the fabrication of complex geometries, including porous NiTi structures. Selective laser melting (SLM) is the most common powder-bed based AM technique [12], which uses a high power-density laser to melt and fuse metallic powders together. So far, two techniques have been used for fabricating porous NiTi structures through AM techniques: (i) decreasing energy input via decreasing laser power (P), increasing scanning speed (v) and/or increasing hatch spacing (h) [13, 14], and (ii) introducing porosity into the CAD 3D models [15]. However, precise and complex porosities can only be achieved via the latter technique. Successful fabrication of SLM NiTi scaffolds has been recently reported $[3,15]$.

A successful porous NiTi implant should not only demonstrate bone-level modulus of elasticity but also it should demonstrate superelasticity behavior at body temperature. This phenomenon occurs at a specific temperature range above the austenite finish $\left(\mathrm{A}_{\mathrm{f}}\right)$ temperature. To decrease the TTs to such temperature ranges, it is necessary to consider a slightly

Behavior and Mechanics of Multifunctional Materials and Composites XII,

edited by Hani E. Naguib, Proc. of SPIE Vol. 10596, 105960H · @ 2018 SPIE

CCC code: $0277-786 \mathrm{X} / 18 / \$ 18 \cdot$ doi: $10.1117 / 12.2305251$ 
Ni-rich NiTi composition as it is reported that TTs drops by the rate of $93{ }^{\circ} \mathrm{C} /$ at.\% with Ni content [16]. Also, Ni-rich NiTi alloys more likely demonstrate superelasticity as they have the higher intrinsic strength and can be precipitation hardened with post heat treatments (i.e, solution annealing, aging). However, if heat treatment would be applied, the TTs may slightly increase due to the formation of Ni-rich precipitates (e.g., $\mathrm{Ni}_{4} \mathrm{Ti}_{3}, \mathrm{Ni}_{3} \mathrm{Ti}_{2}$, and $\mathrm{Ni}_{3} \mathrm{Ti}$ ) [17]. Therefore, an appropriate combination of the alloying composition as well as post heat treatments should be considered to tune the $\mathrm{A}_{\mathrm{f}}$ as well as the superelasticity of the NiTi sample.

The focus of this study was to evaluate the modulus of elasticity and the superelasticity of porous SLM NiTi structures at body temperature. To this aim, several SLM Ni $\mathrm{N}_{50.8} \mathrm{Ti}$ (at.\%) samples with porosity levels ranging from $32 \%$ to $58 \%$ were fabricated through PXM Phenix/3D Systems. Then, appropriate heat treatment was performed on the samples to enhance superelasticity properties of the structures at body temperature. Finally, the superelastic responses and the resulting modulus of elasticity of the samples were evaluated.

\section{METHODS}

\subsection{CAD development}

To create the porous structures, simple cube (SC) porosity type was considered (Note: Porosity is defined as the pore volume divided by the bulk volume). In this type of porosity, as seen in Figure 1, two factors of strut diameter (D) and unit cell length $(\mathrm{L}$ ) had an influence on the porosity level of the structures. To achieve porosity levels of $32 \%, 45 \%$, and $58 \%$, the ratio of the diameter to the length of the struts $(\mathrm{D} / \mathrm{L})$ were considered to be $0.7,0.6$, and 0.5, respectively. For consistency, L was assumed to be $2 \mathrm{~mm}$. For each porous structure, 4 unit cells were considered in each direction (i.e., $\mathrm{x}$ axis, y-axis, and z-axis). Therefore, the dimension of the porous samples was $8 \mathrm{~mm} \times 8 \mathrm{~mm} \times 8 \mathrm{~mm}$, respectively. It should be noted that two plates were also attached to the bottom and top of each porous structure to facilitate the compression testing.

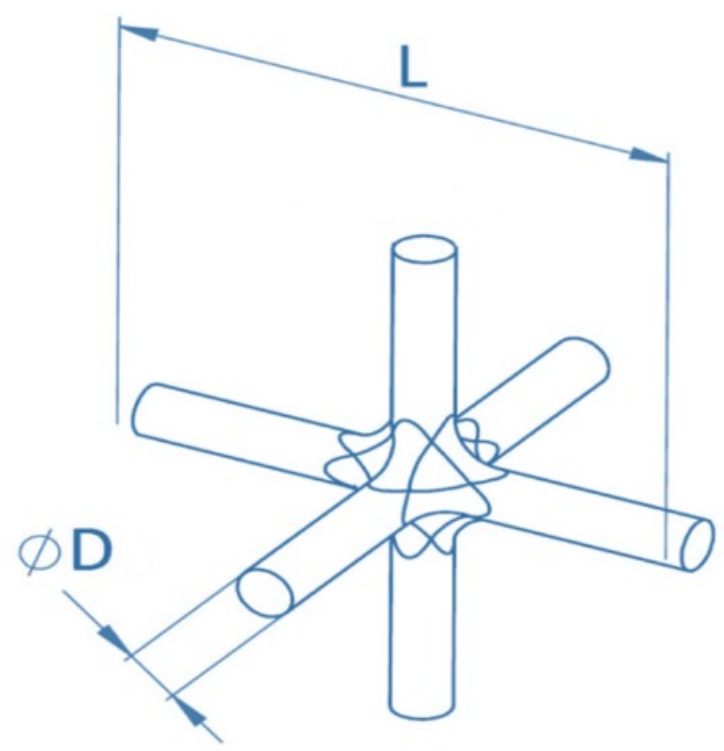

Figure 1. The schematic of a unit cell of the porous structure.

\subsection{Fabrication}

The $\mathrm{Ni}_{50.8} \mathrm{Ti}$ (at.\%) ingot was provided from Nitinol Devices \& Components, Inc. (Fremont, CA), and then, was gas atomized into powder by TLS Technik GmbH (Bitterfeld Germany). The range of $25 \mu \mathrm{m}$ to $75 \mu \mathrm{m}$ was used for the powder particle distribution, as it resulted in the adequate density and impurity, as well as the best flowability [18]. Then, the CAD models were converted into subsequent sliced layers (Note: the geometrical information as well as the SLM processing parameters associated with each layer are assigned in the stage). Finally, SLM fabrication was conducted using a PXM 
Phenix/3D Systems equipped with a $300 \mathrm{~W}$ Ytterbium fiber laser. The optimum parameters were taken from our previous studies (laser power $=250 \mathrm{~W}$, scanning speed $=1.25 \mathrm{~mm} / \mathrm{s}$, powder thickness $=30 \mu \mathrm{m}$, hatching space $=120 \mu \mathrm{m}$, and energy input $\left.=55.5 \mathrm{~J} / \mathrm{mm}^{3}\right)$ [19].

\subsection{Experimental Procedure}

To perform solution annealing, the samples were kept in argon-filled quartz ampoules located within Lindberg/Blue M BF514541 Box furnace. They were held in the furnace at $950^{\circ} \mathrm{C}$ for $5.5 \mathrm{~h}$ and then water quenched. Next, aging treatments were conducted for different time periods at $350^{\circ} \mathrm{C}$ and $450^{\circ} \mathrm{C}$ using a Whip Mix Pro Press 200 furnace. Finally, compression tests were conducted using a $100 \mathrm{kN}$ MTS Landmark servo-hydraulic test machine. Loading was performed at a strain rate of $10^{-4} \mathrm{~s}^{-1}$ while unloading was performed under force control at a rate of $100 \mathrm{~N} / \mathrm{s}$. The strain was measured by an MTS high-temperature extensometer which was attached to the grips.

\section{RESULTS}

\subsection{Phase Transformation Response}

Figure 2 demonstrates the TTs (Austenite finish- $\mathrm{A}_{\mathrm{f}}$, Martensite start- $\mathrm{M}_{\mathrm{s}}$ ) of solutionized SLM Ni ${ }_{50.8} \mathrm{Ti}$ (at. \%) aged at $350^{\circ} \mathrm{C}$ and $450^{\circ} \mathrm{C}$ for different aging times up to $18 \mathrm{hrs}(1080$ mins). It is clear that TTs increase with aging time at both aging temperatures. This can be attributed to the formation of a higher level of Ni-rich precipitates resulting from the increased solubility of Ni with higher temperature. The newly formed precipitates deplete the Ni-content of the NiTi matrix and eventually increase the TTs [20]. For heat treatments longer than 30 mins, it is obvious that the TTs are not significantly changed. In fact, there exists a limitation for the solubility of $\mathrm{Ni}$, which limits the formation of Ni-rich precipitates [21]. In this study, solution annealing at $950{ }^{\circ} \mathrm{C}$ for $5.5 \mathrm{hrs}$ and aging at $350^{\circ} \mathrm{C}$ for 15 mins were conducted on the samples, which in turn resulted in $\mathrm{A}_{\mathrm{f}}$ temperature less than body temperature.

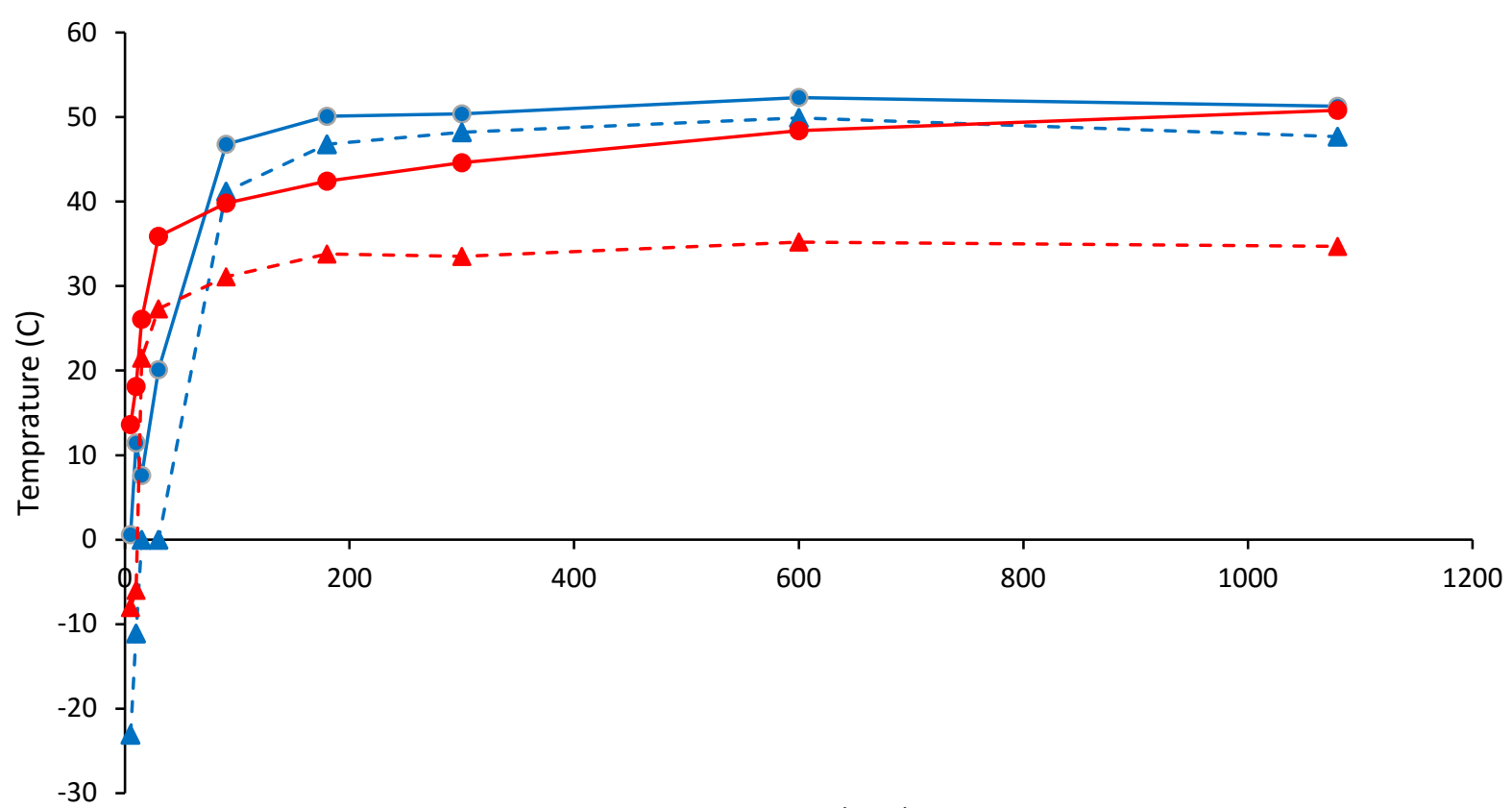

Aging time (Min)

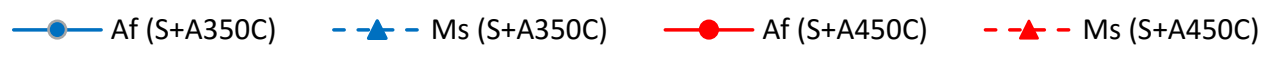

Figure 2. Transformation temperatures (TTs) of solutionized SLM Ni ${ }_{50.8} \mathrm{Ti}$ (at.\%) alloys aged at $350{ }^{\circ} \mathrm{C}$ and $450^{\circ} \mathrm{C}$ as a function of aging time. ( $\mathrm{S}=$ solution annealing, $\mathrm{A}=$ aging) 


\subsection{Superelastic Response}

Figure 3 (a) shows the stress-strain plot of the dense sample loaded till $800 \mathrm{MPa}$ and then unloaded for 10 cycles at body temperature. It is clear that superelasticity is induced in the sample after 10 cycles training. The stabilized response demonstrates strain recovery of $3.0 \%$ while the total irrecoverable strain is $3.6 \%$ at $37^{\circ} \mathrm{C}$. Figure 3 (b)-(d) demonstrate similar response for porous structures loaded and unloaded with $4 \%$ strain limit in the first cycle, and with constant stress limit for the subsequent cycles (Note: the stress limit is $544 \mathrm{MPa}, 440 \mathrm{MPa}$, and $336 \mathrm{MPa}$ stress for 32, 45 and 58\% porous samples, respectively). Obviously, poorer superelastic response (i.e, higher irrecoverable strain) is observed for the samples with higher porosity levels. In the first cycle, both $32 \%$ and $45 \%$ porous samples present strain recovery of $3.5 \%$ while $58 \%$ porous structure shows strain recovery of $2.7 \%$. Similarly, the last cycle of both $32 \%$ and $45 \%$ porous structures show a full strain recovery of $2.75 \%$ while $1.75 \%$ strain recovery is observed for $58 \%$ porosity.
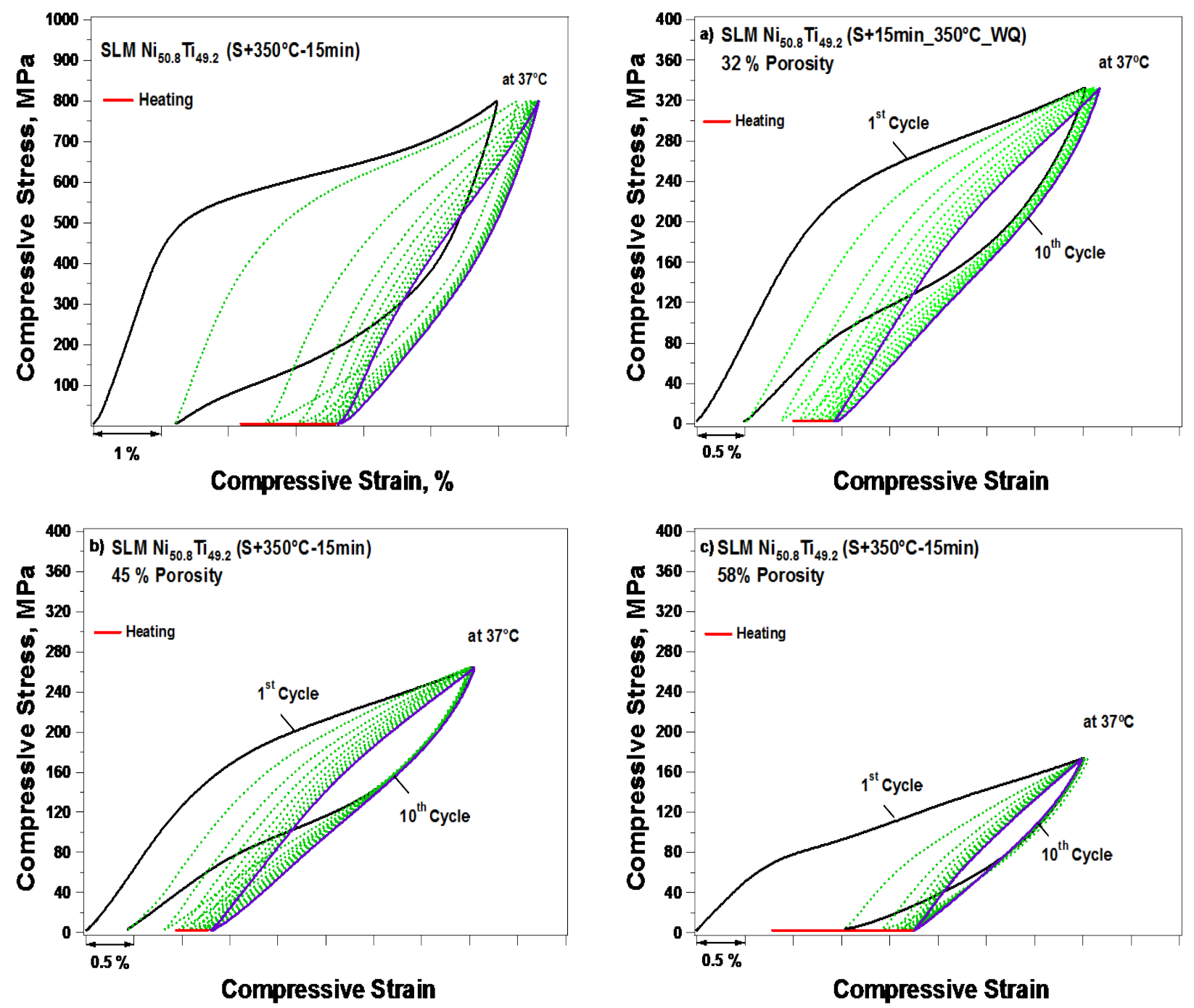

Figure 3. Superelastic response of solutionized dense and porous SLM Ni $i_{50.8} \mathrm{Ti}$ (at.\%) samples aged at $350^{\circ} \mathrm{C}$ for 15 minutes. 


\subsection{Modulus of Elasticity}

Figure 4 (a) and (b) demonstrate stress-strain plots of the dense and porous structures in the $1^{\text {st }}$ cycle and after $10^{\text {th }}$ cycles, respectively. To calculate the modulus of elasticity of each sample, the slope in the elastic region of the plot is calculated and presented in Table 1. The table indicates that modulus of elasticity of dense SLM NiTi drops from 47 GPa to $9 \mathrm{GPa}$ in the first cycle by adding 58\% porosity. It is notable that the modulus of elasticity of each sample is different in the $1^{\text {st }}$ cycle compared to that in the $10^{\text {th }}$ cycle. For example, the modulus of elasticity of $32 \%$ porous sample is $18 \mathrm{GPa}$ and $16 \mathrm{GPa}$ in the $1^{\text {st }}$ cycle and $10^{\text {th }}$ cycles, respectively. One should consider this discrepancy in the modulus of elasticity of the as-fabricated sample versus the stabilized condition.
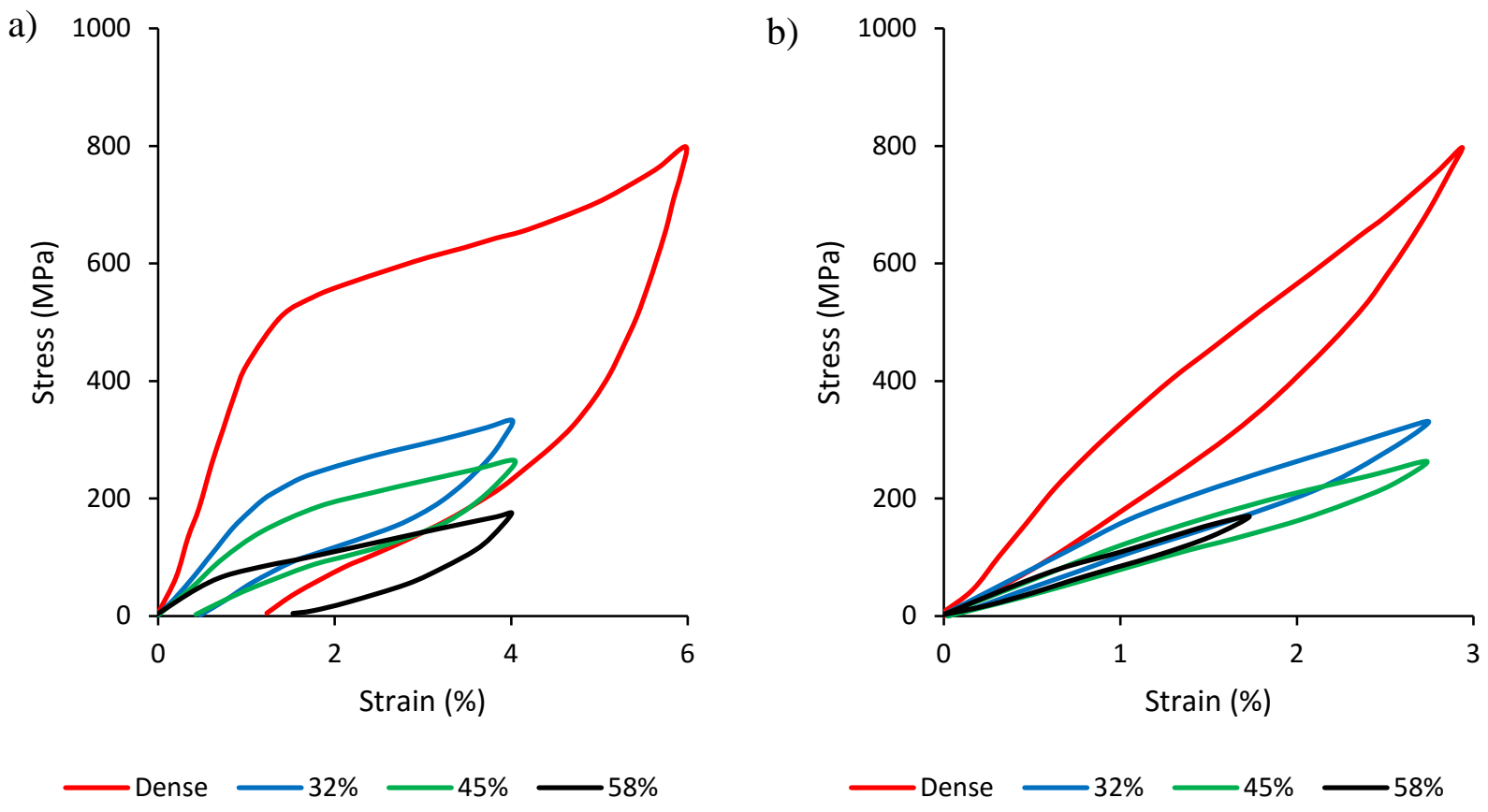

Figure 4. Stress-strain responses of dense and porous SLM NiTi structures (a) in the $1^{\text {st }}$ cycle, and (b) in the $10^{\text {th }}$ cycle.

Table 1. Variation of the modulus of elasticity of SLM Ni $\mathrm{S}_{50.8} \mathrm{Ti}$ (at.\%) with porosity at body temperature.

\begin{tabular}{ccccc}
\hline Porosity (\%) & 0 & 32 & 45 & 58 \\
\hline $\begin{array}{c}\text { st } \text { Cycle Modulus of } \\
\text { Elasticity (GPa) }\end{array}$ & 47 & 18 & 13 & 9 \\
$\begin{array}{c}\mathbf{1 0}^{\text {th }} \text { Cycle Modulus of } \\
\text { Elasticity (GPa) }\end{array}$ & 34 & 16 & 12 & 12 \\
\hline
\end{tabular}

\section{SUMMARY AND CONCLUSION}

Dense and porous SLM Ni50.8 $\mathrm{Ti}$ (at.\%) parts with porosity level ranging from 32\% to 58\% were fabricated. To tune the working temperature of the samples in a way to demonstrate superelasticity at body temperature, a wide range of solution annealing and aging treatments were evaluated, and finally, solution annealing at $950^{\circ} \mathrm{C}$ for $5.5 \mathrm{hrs}$ and aging at $350^{\circ} \mathrm{C}$ for 15 mins were chosen. The conclusions of this study are summarized as following: 
- TTs increase with aging time at both aging temperatures, i.e., $350^{\circ} \mathrm{C}$ and $450^{\circ} \mathrm{C}$. For heat treatments longer than $30 \mathrm{~min}$, it is obvious that the TTs are not significantly changed.

- In the first cycle, the superelastic response of $32 \%$ and $45 \%$ porous samples recover $3.5 \%$ of $4 \%$ of the deformation, while $58 \%$ porous sample recover only $2.7 \%$. Similarly, in the last cycle, $32 \%$ and $45 \%$ porosity demonstrate $2.75 \%$ strain recovery, but the $58 \%$ porosity shows degraded superelastic response with $1.75 \%$ strain recovery.

- The modulus of elasticity of dense SLM NiTi drops from 47 GPa to 9 GPa in the first cycle by adding $58 \%$ porosity. It is notable that the modulus of elasticity of each sample is different in the $1^{\text {st }}$ cycle compared to that in the $10^{\text {th }}$ cycle.

Therefore, it can be concluded that the superelasticity, as well as the modulus of elasticity of the porous structures, can be tuned to those of bone's characteristics. The other influencing factors are porosity type and SLM processing parameters, which open a promising window for future works.

\section{ACKNOWLEDGMENTS}

The authors would like to acknowledge the financial support provided for the project "Nitinol Commercialization Accelerator” by the Ohio Department of Development through Grants WP 10-010, and TVSF awards.

\section{REFERENCES}

[1] A. Bansiddhi, T. Sargeant, S. Stupp et al., "Porous NiTi for bone implants: a review," Acta biomaterialia, 4(4), 773-782 (2008).

[2] M. Mahtabi, N. Shamsaei, and M. Mitchell, "Fatigue of Nitinol: The state-of-the-art and ongoing challenges,” journal of the mechanical behavior of biomedical materials, 50, 228-254 (2015).

[3] N. S. Moghaddam, A. Amerinatanzi, S. Saedi et al., "Stiffness Tuning of NiTi Implants Through Aging." V001T02A014-V001T02A014.

[4] N. Shayesteh Moghaddam, A. Jahadakbar, A. Amerinatanzi et al., "Fixation Release and the Bone Bandaid: A New Bone Fixation Device Paradigm,” Bioengineering, 4(1), 5 (2017).

[5] R. D. Grafton, and E. M. Wolf, [Bone implant] Google Patents, (1999).

[6] L. J. Gibson, and M. F. Ashby, [Cellular solids: structure and properties] Cambridge university press, (1997).

[7] A. Amerinatanzi, H. Zamanian, N. Shayesteh Moghaddam et al., "Application of the Superelastic NiTi Spring in Ankle Foot Orthosis (AFO) to Create Normal Ankle Joint Behavior,” Bioengineering, 4(4), 95 (2017).

[8] A. Nafari, and H. Sodano, "Surface morphology effects in a vibration based triboelectric energy harvester,” Smart Materials and Structures, 27(1), 015029 (2017).

[9] B. V. Krishna, S. Bose, and A. Bandyopadhyay, "Fabrication and characterization of porous Ti6Al4V parts for biomedical applications using electron beam melting process,” J Acta Biomater, 3, 997-1006 (2007).

[10] I. Shishkovsky, L. Volova, M. Kuznetsov et al., "Porous biocompatible implants and tissue scaffolds synthesized by selective laser sintering from Ti and NiTi,” Journal of Materials Chemistry, 18(12), 1309-1317 (2008).

[11] N. S. Moghaddam, M. T. Andani, A. Amerinatanzi et al., "Metals for bone implants: safety, design, and efficacy,” Biomanufacturing Reviews, 1(1), 1 (2016). 
[12] N. S. Moghaddam, A. Jahadakbar, A. Amerinatanzi et al., "Recent Advances in Laser-Based Additive Manufacturing," Laser-Based Additive Manufacturing of Metal Parts: Modeling, Optimization, and Control of Mechanical Properties, (2017).

[13] T. Habijan, C. Haberland, H. Meier et al., "The biocompatibility of dense and porous nickeltitanium produced by selective laser melting,” Materials Science and Engineering: C, 33(1), 419-426 (2013).

[14] M. Elahinia, N. S. Moghaddam, A. Amerinatanzi et al., "Additive manufacturing of NiTiHf high temperature shape memory alloy,” Scripta Materialia, 145, 90-94 (2018).

[15] M. Speirs, S. Dadbakhsh, S. Buls et al., "The effect of SLM parameters on geometrical characteristics of open porous NiTi scaffolds." 309.

[16] W. Tang, "Thermodynamic study of the low-temperature phase B19' and the martensitic transformation in near-equiatomic Ti-Ni shape memory alloys,” Metallurgical and Materials Transactions A, 28(3), 537-544 (1997).

[17] M. Elahinia, N. S. Moghaddam, M. T. Andani et al., "Fabrication of NiTi through additive manufacturing: a review,” Progress in Materials Science, 83, 630-663 (2016).

[18] S. F. S. Shirazi, S. Gharehkhani, M. Mehrali et al., "A review on powder-based additive manufacturing for tissue engineering: selective laser sintering and inkjet 3D printing," Science and Technology of Advanced Materials, 16(3), 033502 (2015).

[19] S. Saedi, N. S. Moghaddam, A. Amerinatanzi et al., "On the effects of selective laser melting process parameters on microstructure and thermomechanical response of Ni-rich NiTi,” Acta Materialia, 144, 552-560 (2018).

[20] X. Zhang, H. Liu, B. Yuan et al., "Superelasticity decay of porous NiTi shape memory alloys under cyclic strain-controlled fatigue conditions,” Materials Science and Engineering: A, 481, 170-173 (2008).

[21] S. Saedi, A. S. Turabi, M. T. Andani et al., "Texture, aging, and superelasticity of selective laser melting fabricated Ni-rich NiTi alloys,” Materials Science and Engineering: A, 686, 110 (2017). 